\title{
WAVE OVERWASH ON A ROCK PLATFORM: REMOTE SENSING AND PRESSURE SENSOR OBSERVATIONS
}

\author{
Hannah E. Power, University of Newcastle, Australia, hannah.power@newcastle.edu.au \\ Michael A. Kinsela, NSW Office of Environment and Heritage, Australia, Michael.Kinsela@environment.nsw.gov.au \\ Caio E. Stringari, University of Newcastle, Australia, caio.eadistringari@uon.edu.au \\ Murray J. Kendall, University of Newcastle, Australia, murray.kendall@uon.edu.au \\ David J. Hanslow, NSW Office of Environment and Heritage, Australia, David.Hanslow@environment.nsw.gov.au
}

\begin{abstract}
INTRODUCTION
Open ocean rocky shore platforms are typically exposed to high wave energy and are often the location of recreational activities from sightseeing and walking to fishing (Kennedy et al. 2017). The exposure of these environments, combined with the use for recreation, results in a high level of risk for those who use the rock platform. In Australia, for example, $19 \%$ of coastal fatalities occur on rock coasts, most commonly when individuals fall from microtidal semi-horizontal platforms into the ocean (SLSA, 2014a,b). Managing the hazards and resultant risk on rocky shore platforms requires a different approach to that taken for sandy beaches as the sites are typically remote. Here we explore the wave overwash hazards on a remote but high visitation rocky shore platform $40 \mathrm{~km}$ south of Sydney, Australia.
\end{abstract}

\section{STUDY SITE}

The Figure 8 Rock Platform is located approximately 40 $\mathrm{km}$ south of Sydney, Australia and is exposed to open ocean swell (Figure 1; Kinsela et al., 2017). The site features unique pools that have been weathered into the platform and is a site that is visited by national and international tourists. Recent increases in visitation and visitor injuries have led to a project to develop a predictive model for wave overwash hazards at the site.

This paper uses video remote sensing and pressure sensor observations to assess the wave overwash and wave energy dissipation across the rocky shore platform with comparisons with offshore wave rider buoy data.

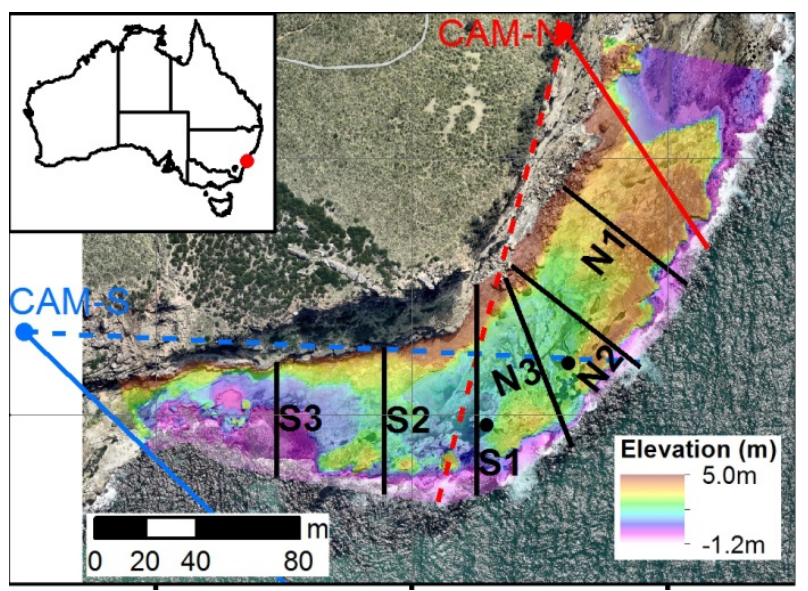

Figure 1 - Site map showing the two camera locations (red and blue dots) and their fields of view (red and blue lines) along with the six cross-platform transects analysed using video data (N1, N2, N3, S1, S2, and S3; black lines) and the locations of the two pressure sensors (black dots).

\section{DATA COLLECTION AND RESULTS}

Two low cost camera systems were installed at the site in March 2017. Both systems recorded snapshots at $1 \mathrm{~Hz}$ for 20 minutes of each daylight hour until August 2017. Snapshots were rectified using ground control points and timestacks of 20 minute durations were created along six cross-platform transects (Figure 1). Pixel values in the timestacks were converted to a percentage of time of inundation using a combination of pixel lightness and pixel colour temperature (e.g., Figure 2a). For the period 29 March to 7 April 2017, two pressure sensors were deployed in the rock pools at the site that recorded continuously at $8 \mathrm{~Hz}$ for the duration of the deployment. During this period, nearshore significant wave height peaked at $2.99 \mathrm{~m}$ and depths on the platform exceeded $3 \mathrm{~m}$ (see Figure 2).

In the conference presentation, we examine the relationship between offshore wave conditions and the degree of wave overwashing on the rocky shore platform to assist in the development of a hazard warning system.
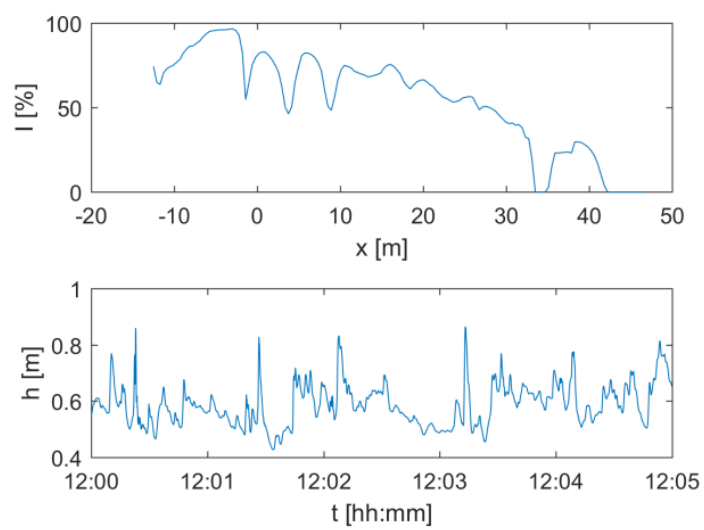

Figure 2 - (a) Percentage of cross-platform inundation (I) along transect N2 on 2 April 2017 at 12:00-12:20pm. (b) Depth over the platform $(h)$ as recorded by the northeastern pressure sensor on 2 April at 12:00-12:05pm.

\section{REFERENCES}

Kennedy, lerodiaconou, Weir, Brighton (2017): Wave hazards on microtidal shore platforms: testing the relationship between morphology and exposure, Natural Hazards, vol. 86, pp. 741-755.

Kinsela, Power, Stringari, Kendall, Morris, Hanslow (2017): Wave process and overwash on a high-energy rock platform, Proc. Coastal Dynamics 2017, pp. 685-696

SLSA (2014a): Annual report 2013/14, Surf Life Saving Australia, Sydney.

SLSA (2014b): National Coastal Safety Report 2014, Surf Life Saving Australia, Sydney. 